An official publication of the International Society for Energy, Environment and Sustainability (ISEES)
Journal of Energy and
Environmental Sustainability
Journal homepage : www.jees.in

\title{
Production of ethanol by Zymomonas mobilis using partially purified glycerol
}

\author{
S. Chozhavendhan ${ }^{1,5}$, R. Praveen Kumar ${ }^{1}$, S. Sivarathnakumar ${ }^{1}$, J. Vinoth Arulraj ${ }^{1}$, S. Elavazhagan ${ }^{2}$, \\ B. Bharathirja ${ }^{3}$, Sunita J Varjani ${ }^{4}$
}

${ }^{1}$ Arunai Engineering College, Tiruvannamalai, Tamilnadu.

${ }^{2}$ Shantha Biotechnics Private Limited, Hyderabad, Telangana.

${ }^{3}$ Vel Tech High Tech Dr.RR Dr.SR Engineering College, Chennai, Tamilnadu.

${ }^{4}$ Gujarat Pollution Control Board, Gandhinagar, Gujarat.

${ }^{5}$ Selvam College of Technology, Namakkal, Tamilandu.

\section{A R T I C L E I N F O}

Received : 30 August 2017

Revised : 04 October 2017

Accepted : 15 October 2017

Keywords:

Ethanol, Zymomonas mobilis, Crude glycerol, GC-MS, GC-FID

\begin{abstract}
A B S T R A C T
Glycerol obtained as a by-product from oleo chemical industries was effectively utilized as a substrate for the production of several value-added bio products such as acetic acid, citric acid, DHA, ethanol, etc. It has several advantages over commercial substrates which includes low cost nutrients, as a good carbon and energy source for the microorganisms to grow with high product conversion rate. The product formation was lowered due to the copious impurities present in the crude glycerol sample. The impurities present in the crude glycerolwere removed by two stage purification process. Purification process helps to increases the initial concentration of glycerol from $10 \%(\mathrm{v} / \mathrm{v})$. The resulting partially purified glycerol when used as a substrate produces $33.44 \%(\mathrm{v} / \mathrm{v})$ of ethanol with $27 \%(\mathrm{v} / \mathrm{v})$ concentration after simple distillation using Zymomonas mobilisat $\mathrm{pH} 6$ and temperature $36^{\circ} \mathrm{C}$. The partially purified substrate and the product ethanol were validated by GC-MS and GC-FID.
\end{abstract}

\section{Introduction}

Invention of new machines and instruments necessitates lots of energy for running their application. For the energy needs, wemostly depend on fossil fuels [Vijay Kumaret al., 2016]. Depletion of fossil fuels, energy crisis, greenhouse effect and other terms leads the researchers to work on alternate energy source. For the past few years the production of alternate biofuel from renewable resources has exaggeratedly increased. Present day interest in biofuel production is biodiesel and bioethanol, which have high efficiency and its sustainability to the declining of carbon dioxide expulsion and other harmful gas during combustion [Janaun and Ellis, 2010; Girard and Fallot, 2006; Zhu and Beland, 2006]. Due to the increasing production of biodiesel, a surfeit crude glycerol has resulted in the ratio of 10:1 volume [Itoet al., 2005;Moonet al., 2010; Saxenaet al., 2009]. The obtained glycerol contains medleys of methanol, salt, catalyst residue, soap, fatty acids and glycerides [Zul and Saka, 2012]. The crude glycerol from biodiesel production, on the other hand, is dark brown liquid with faulty smell, being dependent greatly on the methods and the feedstocks used for its conversion [Teng et al., 2014]. Without new applications, excess of such crude glycerol could wield impact into the refined glycerol market [Yang et al.,2012] and creating a new waste, which could only be used as low-energy fuel for incineration or ruminant feed [Ciriminna et al.,2014]. Purification of crude glycerol to a chemically pure substance results in a valuable industrial chemical [Higgins 2012]. Glycerol is a building block to many useful derivatives and this has prompted the attention of researchers to explore the conversion of the

\footnotetext{
*Corresponding Author: scv.ibt@gmail.com
}

low-cost glycerol to value-added products like ethanol, citric acid, dihydroxyacetone and so on. Physically, pure glycerol (99\%) is a clear, odorless and hygroscopic liquid under ambient condition. Its boiling point, melting point and flash point are reported to be $290^{\circ} \mathrm{C}, 18^{\circ} \mathrm{C}$ and $177^{\circ} \mathrm{C}$, respectively [Ayoub and Abdullah, 2012]. In this work an attempt has been made to explore the feasibility of the purification and utilization of crude glycerol for the production of primary alcohol (ethanol) using microbial fermentation process. To understand the efficacy of these purification process, it is carried out in two stage purification for the removal of impurities and increment in the concentration of glycerol was discussed elaborately. The biomass production, substrate utilization and product formation were analyzed at regular interval of time during fermentation using Zymomonas mobilis

\section{Material and Methods}

The same batch of crude glycerol sample was procured from Sri Bannari sugars private limited. All other chemicals used in this study were obtained commercially and authentically of analytical grade. Purification of crude glycerol becomes indispensable for the effective utilization as carbon and energy source.

\subsection{Partial purification process}

In this study, crude glycerol was partially purified by simple laboratory methods in two stages. In stage 1 purification process, the major impurities like methanol, salt and soap are removed. Methanol was removed by simple distillation process and acidification with phosphoric acid was 
carried out to recover glycerol rich phase from soluble soap and salt. In stage 2 process,recovered glycerol rich phase was treated with sodium oxalate and adsorption with $1 \%$ activated charcoal to eliminate colour, odour and the other minor impurities present in glycerol rich phase. The glycerol sample was filtered and centrifuged finally to get rid of suspended solids and free floating fatty acids.

\subsection{Analysis}

The concentration of crude glycerol, stage 1 and stage 2 partially purified glycerol were characterized and analyzed using GC-FID (Bruker 430GC) and GC-MS (Agilent MS 5975). Other physical parameters such as density, flash point, fire point etc., carried out by standard methods. In this analysis, removal of impurities and increase in the concentration of glycerol was studied thoroughly in stage wise purification process.

\subsection{Ethanol production process}

Zymomonas mobilis(2427) was procured from MTCC Chandigarh, India was used for the production of ethanol. From the evidence of previous studies, glycerol was prepared with optimized substrate condition $7 \%(\mathrm{v} / \mathrm{v})$ of glycerol and $5 \%$ inoculum concentration was set for the production process of ethanol [Chozhavendhan et. al., 2015]. The concentrated cell was inoculated in $100 \mathrm{ml}$ media containing stage 2 purified glycerol after sterilization at various $\mathrm{pH}$ and temperature. The fermentation was set at the agitation speed of $150 \mathrm{rpm}$ with the $\mathrm{pH}$ range of 5-7 and simultaneously with the temperature in the range of $30-40^{\circ} \mathrm{C}$. The samples were periodically collected for analysis of substrate utilization, biomass growth and product formation. The cell concentration was determined by dry cell weight. The characterization and concentration of produced ethanol was validated by GCMS and GC-FID.

\section{Results \& Discussion}

\subsection{Crude glycerol}

Crude glycerol from biodiesel preparation varies widely in color and physical properties. The sample glycerol was highly viscous liquid with dark brown in colour and possesspH of 9.6 with $10.43 \%$ concentration along with methanol, soap, ash, water and salt as major impurities. Initial concentration and colour of crude glycerol may depend on the production process of the plant [Cesar et al., 2013].

\subsection{Stage 1 purification process.}

Distillation and acidification are the two techniques employed in stage 1 purification process. $250 \mathrm{ml}$ of molten glycerol sample was subjected to distillation at $65^{\circ} \mathrm{C}$ at 20 minutes to recover the excess unreacted methanol. Excess methanol to oil ratio was generally practiced to drive the forward reaction completion [Wan Nor et al., 2014]. The excess methanol settles in glycerol phase. Recovering of pure methanol is inexpensive when compared with purifying glycerol at high boiling point by flashing or distillation. Thus for the economic assessment, the recovered methanolcan be reused again in the transesterification process [Bohon et al., 2011]. The presence of methanol in the sample exerts a negative influence on microbial growth during the fermentation process. The recovered residuewas added with phosphoric acids slowly and constantly with constant agitation to drop down the $\mathrm{pH}$ from alkaline to acidic condition. $\mathrm{pH}$ is dropped down from 9.6 to 4.5 and kept static for 45 minutes for the phase separation to occur in the separating funnel.The neutralization/ acidification separates the reaction mixture into three phases using mineral ions. The addition of $\mathrm{H}^{+}$ions convers the soluble soap into insoluble free fatty acids to float in the top layer. The removal of soap as free fatty acids aids to avoid the bubbles formation during fermentation process. The remaining $\mathrm{H}^{+}$converts the unutilized catalysts used during transesterification process into salt and settles at the bottom. Glycerol rich phase in the middle layer was removed carefully from the separating funnel. [Chozhavendhan et al., 2016a].

\subsection{Stage 2 purification process}

In continuation of the stage 1 process, when the sample was treated with $0.3 \%$ sodium oxalate in $80^{\circ} \mathrm{C}$ for 30 minutes results in the maximum impurity removal rate and shows $44.4 \%$ concentration. Similarly $39.9 \%$ and $42.6 \%$ concentration was achieved at 70 and $90^{\circ} \mathrm{C}$. The action of sodium acetate in removing the impurities was not yet known. Adsorption process was done with $1 \%$ moisture free powdered charcoal at $200 \mathrm{rpm}$ for 5 hours to remove colour and other fatty acids. The powdered charcoal turns colour of glycerol sample from golden yellow to straw yellow fluid. The samples were filtered to remove charcoal using Whatmann filter paper no 1. Centrifugation was performed at $5000 \mathrm{rpm}$ for 5 minutes to remove other suspended solids, salts and free floating fatty acids.

\subsection{Glycerol analysis}

Initial analysis of crude glycerol through GCMS and GCFID reveals that it possesses only $10.43 \%$ glycerol concentration. Apart from major impurities, many other minor impurities like benzoic acid, methyl ester, acetophenone, decanoic acid, cyclododecane methanol, 9-octadecenoic acid, cyclopentadecanone, dexadecanoic acid etc., which are common in biodiesel plant were also present in crude glycerol [Nanda et al., 2014 Chozhavendhan et al., 2016b]. GCMS analysis of stage 1 partially purified glycerol sample shows new compounds of acetic acid and whereas other minor impurities were removed. This was evicted by the peaks attained in GCMS analysis of stage 1 purified glycerol. In stage 2 purified glycerol the GCMS analysis shows a single peak, which states the presence of glycerol alone in the sample as shown in Figure $1 \mathrm{a}, \mathrm{b}, \mathrm{c}$. The partial

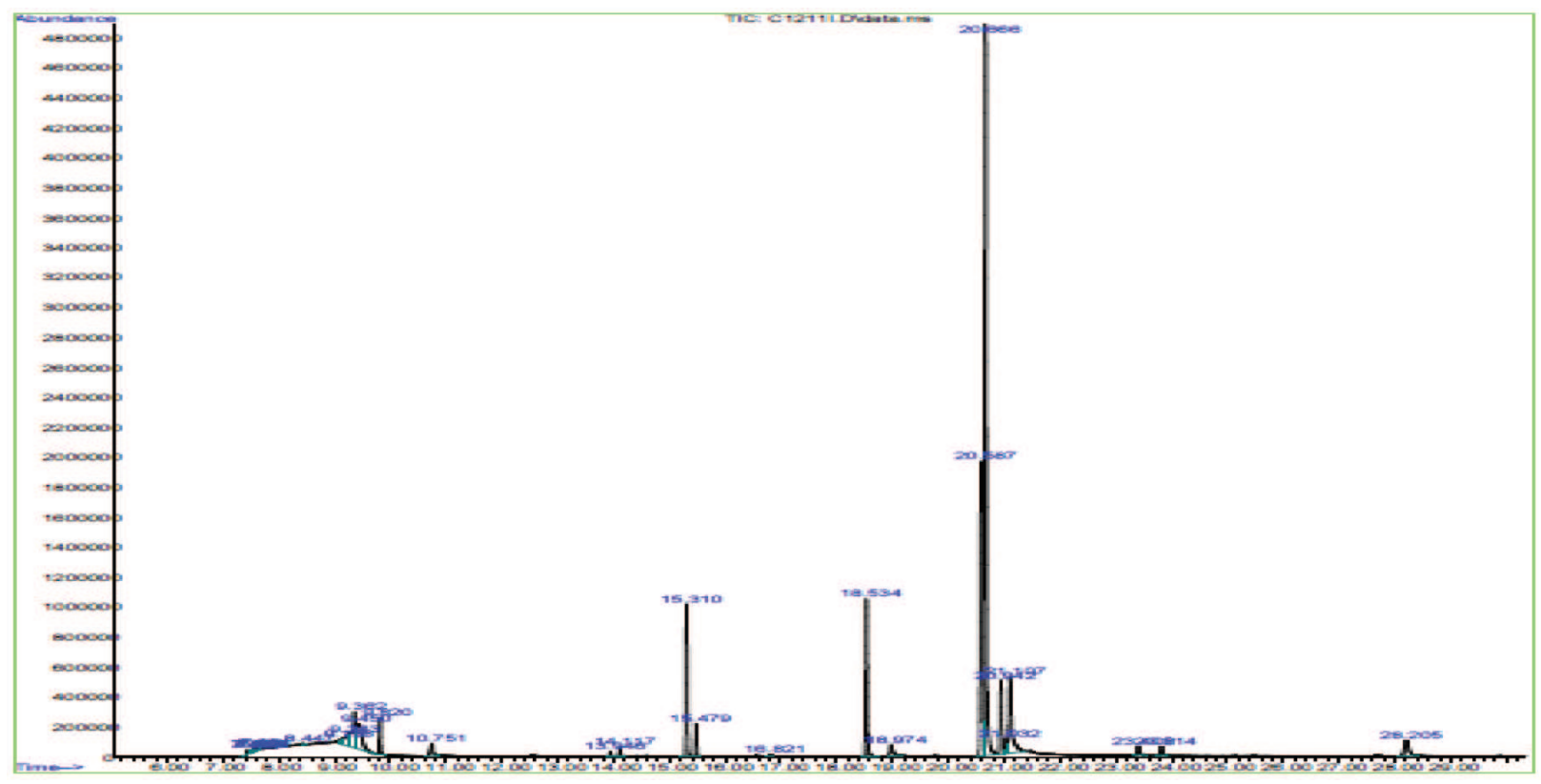

Figure 1.a. GCMS analysis of crude glycerol 


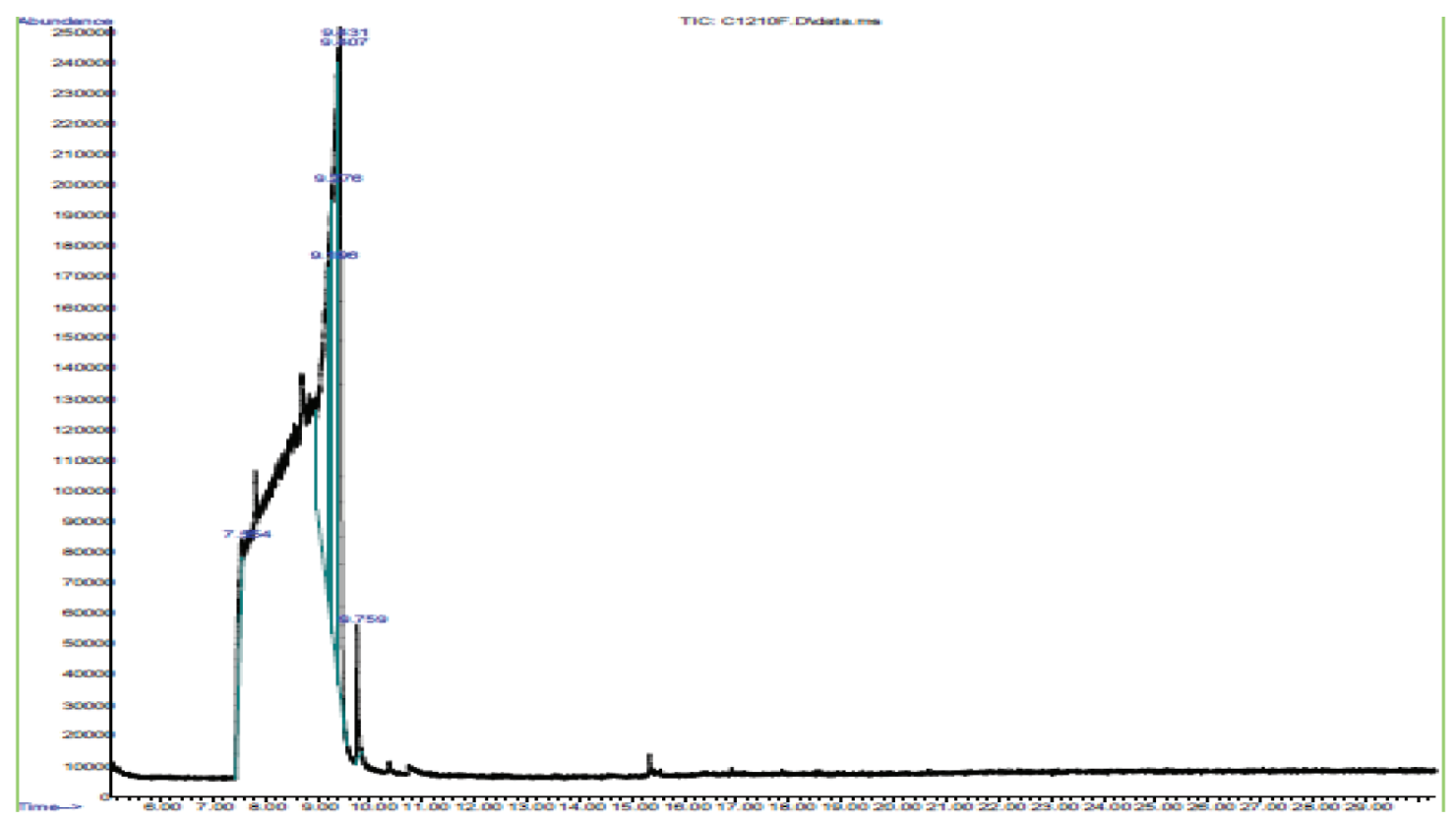

Figure 1.b. GCMS of glycerol sample at the end of stage 1 purification process

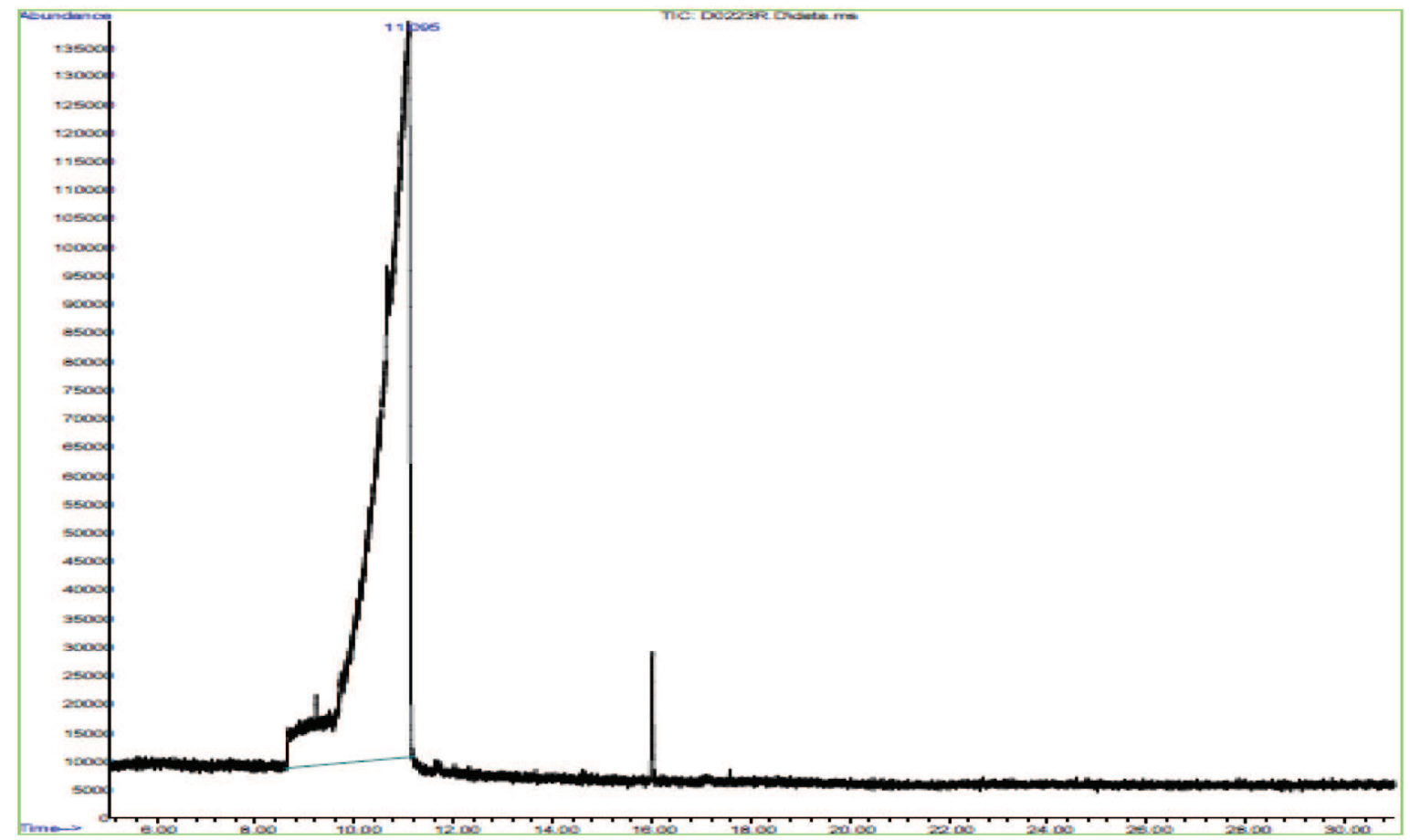

Figure 1.c. GCMS analysis of stage 2 partially purified glycerol

purification process helps to improve the glycerol concentration from $10.43 \%$ to $24.9 \%$ in stage 1 and $44.4 \%$ in stage 2 purification process at $80^{\circ} \mathrm{C}$ with sodium oxalate. The treatment of sodium oxalate at $80^{\circ} \mathrm{C}$ shows maximum removal of impurities when compared with $70^{\circ} \mathrm{C}$ and $90^{\circ} \mathrm{C}$ and the concentration at those temperatures are $39.9 \%$ and $42.6 \%$ respectively. Colour, $\mathrm{pH}$, density, flash point, fire point and other properties of glycerol were compared for crude, stage 1 and stage 2 partially purified glycerol and pure glycerol were displayed in table 1 . Other than the colour and $\mathrm{pH}$ the results of stage 2 purified glycerol was close to commercial glycerol when compared with crude glycerol and stage 1 purified glycerol. 


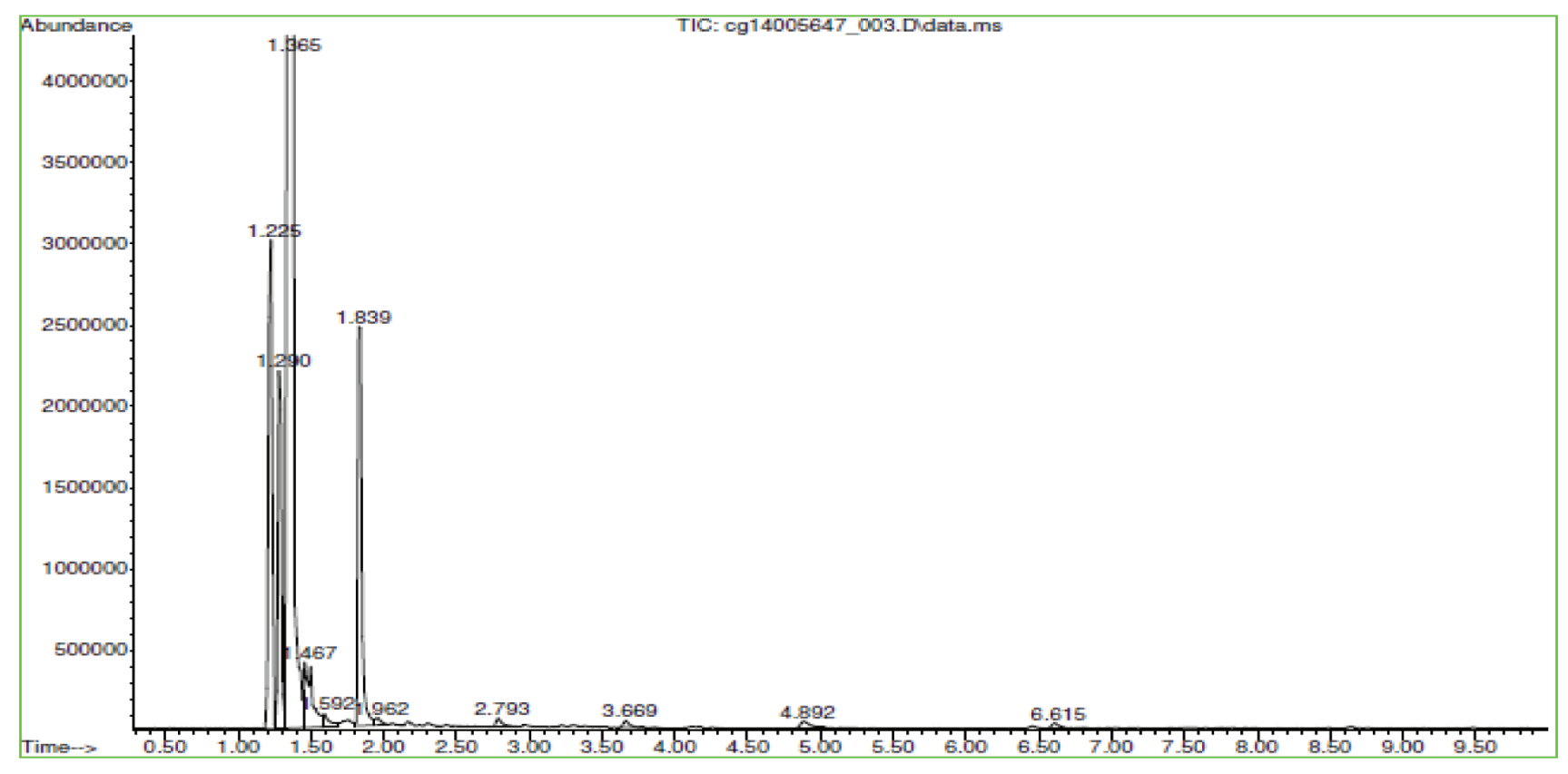

Figure 2. GC-MS analysis of ethanol produced by Z. mobilis

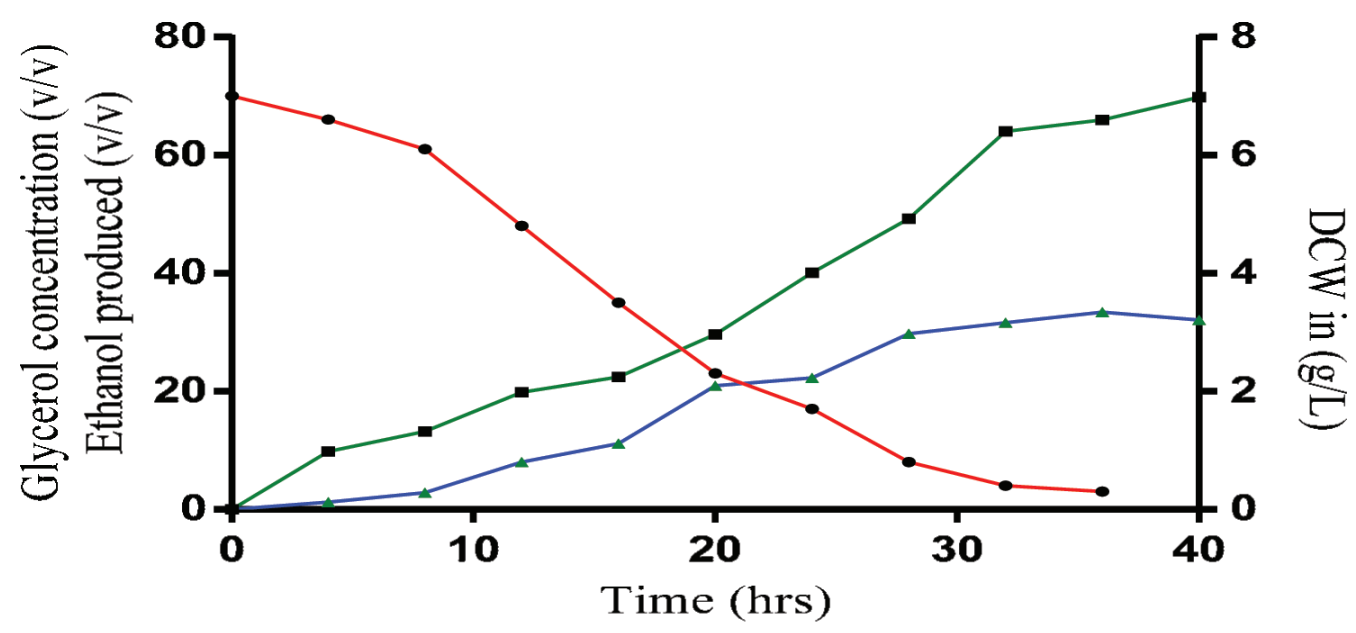

$\rightarrow$ Glycerol uilization by Z. mobilis (v/v)

$\rightarrow$ DCW of $Z$. mobilis $(\mathrm{g} / \mathrm{L})$

$\simeq$ Ethanol produced by $Z$. mobilis (v/v)

Fig 3 DCW, ethanol yield and substrate utilization by $Z$. mobilis for ethanol production 
Table 1. Comparison of crude glycerol, stage 1 and stage 2 partially purified glycerol with properties of pure glycerol

\begin{tabular}{l|l|l|l|l}
\hline Properties & Crude glycerol & Stage 1 purified glycerol & Stage 2 purified glycerol & Commercial pure glycerol \\
\hline Colour & Dark brown & Golden yellow & Straw yellow & Colourless \\
\hline $\mathrm{pH}$ & 9.6 & 4.5 & 5 & 6.7 \\
\hline Density $(\mathrm{kg} / \mathrm{m} 3)$ & 1.29 & $1.23 \pm 0.2$ & $1.23 \pm 0.2$ & 1.25 \\
\hline Flash point $\left({ }^{\circ} \mathrm{C}\right)$ & 180 & 196 & 214 & 177 \\
\hline Fire point $\left({ }^{\circ} \mathrm{C}\right)$ & 211 & 230 & 12 & 204 \\
\hline Carbon residue $\%$ & 18 & 13 & 0.14 & 11.25 \\
\hline Ash content $\%$ & 11.26 & 0.16 & Miscible & 0.132 \\
\hline Solubility with water & Miscible & Miscible & Miscible \\
\hline
\end{tabular}

\subsection{Ethanol production}

From the previous studies $Z$. mobilis is capable of producing ethanol from partially purified glycerol. At all set $\mathrm{pH}$ in the range of 5-7 and 30$40^{\circ} \mathrm{C}$ the $Z$. mobilis can able to grow well and produce ethanol. The product ethanol after double distillation was validated by GCMS and GC-FID as shown in the fig 2. Substrate containing 7\% (v/v) of glycerol and $5 \%$ inoculum concentration of $Z$. mobilis produces maximum yield of $33.44 \%(\mathrm{v} / \mathrm{v})$ of distillate ethanol with at $\mathrm{pH} 6$ with $36^{\circ} \mathrm{C}$. In $33.44 \%$ volume, the ethanol concentration was found to be $27 \%$ from GC-FID analysis while the remaining volume constitutes byproducts such as methyl alcohol, isopropanol, acetic acid, butanoic acid and propionic acid etc., as revealed by GCMS study. Fig 3 shows biomass production, substrate utilization and ethanol production. In this process, a very close result was also obtained at $7 \%$ substrate and $5 \%$ inoculum concentration at $\mathrm{pH} 6$ with $34^{\circ} \mathrm{C}$ yields $31.60(\mathrm{v} / \mathrm{v})$ of distillate ethanol with the concentration of ethanol $26.8 \%$ by GC-FID analysis. At otherpH and temperature biomass growth and ethanol production was comparatively low.

\section{Conclusion}

The impurities present in the crude glycerolinhibit effective utilization of crude glycerol by the microorganism for the production of value added products. Purification of glycerol and production of ethanol from crude glycerol is economical than producing ethanol from conventional sources like molasses and corn starch because market value of crude is very low. Also, those industries enjoy numerous benefits like self-disposal of crude glycerol, zero liquid discharge and eliminates the risk contamination followed by legal sanctions. Purified glycerol was stored and further used in for the production of ethanol and other products. $Z$. mobilis could able to convert the glycerol into ethanol, particularly $7 \%$ $(\mathrm{v} / \mathrm{v})$ substrate, $5 \%(\mathrm{v} / \mathrm{v})$ inoculum concentration, $\mathrm{pH} 6$ and temperature $36^{\circ} \mathrm{C}$ could able achieve more ethanol yield than at other $\mathrm{pH}$ and temperature.

\section{Reference}

1. Ayoub M, Abdullah AZ, 2012,Critical review on the current scenario and significance of crude glycerol resulting from biodiesel industry towards more sustainable renewable energy industry, Renewable and Sustainable Energy Reviews, Vol. 16, pp. 2671-2686.

2. Bohon MD, MetzgerBA, LinakWP, KingCJ,Roberts WL,2001, Glycerol combustion and emission, Proceedings of the combustion Institute, Vol. 33, pp. 2717- 2724

3. Cesar AGQ, ChristainJRC, Joao AC,2013, Glycerol: production, consumption, prices, characterization and new trends in combustion, Renewable and Sustainable Energy Reviews, Vol. 27, pp. $475-493$.

4. Chozhavendhan S, Praveen Kumar R, Sivarathnakumar S, Kirubalini G, BarathirajaB, Jayakumar M,2015, A Comparative analysis on microbial production of primary alcohols using pretreated glycerol, Asian Jr. Microbiol. Biotech. Env. Sc., Vol. 17, pp. 9-13.

5. Chozhavendhan Sivasankaran, Praveen Kumar Ramanujam, Bharathiraja Balasubramanian, Jayakumar Mani, 2016a, Recent progress on transforming crude glycerol into high value chemicals: a critical review, BIOFUELS, http://dx.doi.org/ 10.1080/17597269.2016.1174018.

6. Chozhavendhan S, Praveen Kumar R, Kirubalini G, Jayakumar M, 2016 b,Purification and Characterization of Waste Stream Glycerol Derived from Biodiesel Industry,Journal of Environmental Biology, Vol. 37, pp. 1539-1534.

7. Ciriminna R, PinaCD, Rossi M, Pagliaro M, 2014, Understanding the glycerol market, Eur J Lipid Sci Technol, Vol. 116:pp. 1432-1439.

8. Girard P, FallotA, 2006, Review of existing and emerging technologies for the production of biofuels in developing countries, Energy Sustainable Dev, Vol. 10 pp. 92-108.

9. Higgins J, 2002, On the road to fueling the future, In: Bioenergy '02, proceedings, paper 2062. Boise, I.D, September: published by Pacific Regional Biomass Energy Program.

10. Ito T, Nakashimada Y, Senba KK, Matsui T, Nishio N, 2005, Hydrogen and ethano production from glycerol-containing wastes discharged after biodiesel manufacturing process, J Biosci Bioeng, Vol. 100, pp. 260-65.

11. Janaun J,Ellis N, 2010, Perspectives on biodiesel as a sustainable fuel, Renewable Sustainable Energy Rev, Vol.14,pp. 1312-1320.

12. MoonC, J-Ahn H, Kim SW, Sang B,Um YY, 2010, Effect of biodiesel derived raw glycerol on 1,3-Propanediol production by different microorganisms, App Biochem Biotech, Vol. 161, pp. 502-10.

13. Nanda MR, YuvanZ, QinW, Poirier MA, Chunboa X,2014, Purification of crude glycerol using acidification: Effects of acid types and product characterization, Austin J Chem Eng, Vol. 1(1), pp. 1-7.

14. Saxena RK, Anand P, Saran S, Isar J, 2009, Microbial production of 1,3-Propanediol Recent developments and emerging opportunities, Biotechnol Adv, Vol. 27, pp. 895-913.

15. TengWK, Ngoh GC, Yusoff R, Aroua MK, 2014, A review on the performance of glycerol carbonate production via catalytic transesterification: effects of influencing parameters, Energy Convers Manag, Vol. 88, pp. 484-497.

16. Vijay Kumar G, Uttara S, Amrita B, 2016, Bioconversion technologies of crude glycerol to value added industrial products, Biotechnology Reports, Vol.09, pp. 9-14.

17. Wan Nor RWI, Zatil AC,Manal I, Jamaliah MJ, Mohd AY, 2015, Recovery and Purification of Crude Glycerol fromVegetable Oil Transesterification, Separation \& Purification Reviews, Vol44, pp. 250-267.

18. Yang F, Hanna MA, Sun R, 2012, Value-added uses for crude glycéro -a byproduct of biodiesel production, Biotechnol Biofuels, Vol. 5, pp. 1-10.

19. Zhu H, Beland M, 2006, Evaluation of alternative methods of preparing hydrogen producing seeds from digested wastewater sludge, Int. J Hydrogen Energy, Vol. 31, pp. 1980-88.

20. Zul I, Shiro S,2016, Esterification of glycerol from biodiesel production to glycerol carbonate in non catalytic supercritical dimethyl carbonate' SpringerPlus, Vol. 5, pp. 1-6. 